\title{
Global migration processes analysis and modelling of migration attractive- ness of countries through fuzzy logic
}

\author{
Hanna Danylchuk ${ }^{1, *}$, Liubov Kibalnyk ${ }^{1, * *}$, Oksana Kovtun ${ }^{2, * * *}$, Oleg Pursky ${ }^{3, * * * *}$, and Zenon Stachowiak ${ }^{4, \dagger}$ \\ ${ }^{1}$ The Bohdan Khmelnytsky National University of Cherkasy, 81 Shevchenko Blvd., Cherkasy, 18031, Ukraine \\ ${ }^{2}$ State Institution of Higher Education "University of Educational Management”, 52A Sichovykh Striltsiv Str., Kyiv, 04053, Ukraine \\ ${ }^{3}$ Kyiv National University of Trade and Economics, 19 Kyoto Str., Kyiv, 02156, Ukraine \\ ${ }^{4}$ Cardinal Stefan Wyszyński University, 5 Dewajtis Str., 01-815 Warsaw, Poland
}

\begin{abstract}
The article deals with the analysis the current state of migration in the context of globalization and identifies the most important corridors for the labour movement. The main donor countries of migrants are developing countries, with low socio-economic indicators, difficult environmental conditions and high levels of poverty. According to forecasts, the most migratory flows will take place in the countries of North America and in Europe, which is due to rising trends in unemployment in the countries of the "third world" and the demand for cheap labour, changes in the structure of the economies of developed countries, changes in labour market demand. The main world regional corridors in 1990-2019 have been identified through statistical analysis. And their growing and declining trends. The need to use economic and mathematical modelling techniques to analyse and determine the migration attractiveness of recipient countries in an uncertain environment has been substantiated. It has been shown that fuzzy logic tools are the most effective in this case. Based on the results of the simulation using the Mamdani method, the world's attractiveness rating for migration is calculated, which with a "high" thermo leads such countries as Italy, France, United Arab Emirates. The findings suggest that migrants are attracted by countries with the lowest inflation rates, high and average GDP per capita and average or low taxation levels.
\end{abstract}

\section{Introduction}

Since the 19th century, international labour migration has been the subject of scientific research in various fields. Since the late 1980s and early 1990s, population migration as a social and economic phenomenon has become particularly relevant and global in the context of the development of integration processes which have led to a significant labour movement. Today, migration is characterized by the permanence of territorial flows and the diversity of expression forms. Changes in migration flows are mainly reflected in population growth, territorial movements and the emergence of new types of migration movements. Migration processes have a decisive impact on the socio-economic development of countries and regions as a whole.

By D. Massey [1] the period of post-industrial migration (since the mid-1960s) has been associated with its emergence as a global phenomenon cause of the number and diversity of donor and recipient countries dramatically increasing. Developing countries, third world countries, have intercepted the baton of dominant donors of migrants.

\footnotetext{
*e-mail: abdanilchuk@gmail.com

**e-mail: liubovkibalnyk@gmail.com

***e-mail: kovtun.oa71@gmail.com

****e-mail: Pursky_o@ukr.net

$\dagger$ †-mail: zenstach@wp.pl
}

The main flows of migrants were from industrialized countries to post-industrial ones.

The second wave of globalization (from about 1950-s to 1980-s) led to the migration movement from less developed countries (Afghanistan, Pakistan, India, Vietnam, Morocco, Egypt, Turkey, etc.) to more developed West and East countries (Europe, USA, Canada, Japan, etc.). Most migrants were low-skilled workers, employed under temporary employment programmes. In the early 1980s such Asian countries as Korea, Taiwan, Hong Kong, Singapore, Malaysia and Thailand experienced migration.

During the second and the beginning of the third wave of globalization, along with the traditional countries of immigration like the United States, Canada, and Australia, some European countries (Germany, France, etc.) began to accept migrants actively. During that period, the number of migrants in the world rose sharply. From 1970-s to 1980-s there were 82 million people migrants and, in 1980, there were 99 million people. Over the next 10 years, the number of international migrants increased by 56 million people [2].

Recently, many scholars believe that the end of the twentieth and the beginning of the twenty-first century is a phase of unprecedented international migration. However, other researchers, notably M. J. Miller and S. Castles refers to this assumption as a "myth", as the number of migrants in the world is growing, but their share in the world 
population does not exceed 2-3\% in the history of migration [3]. More than a century ago, during the period of mass migration to the New World, the share of migrants in the world did not exceed $3 \%$ of the world's population, so authors [4] refer to the opinion of M. J. Miller and S. Castles about false migration. It should be noted, however, that the scale of international migration in recent decades has never been greater in the history of human development.

In our view, international migration should be seen as a widespread socio-economic process with many causes and consequences, playing a significant role in the economic, inter-ethnic and demographic changes in the development of communities and society as a whole. It have a projection in the social, political and cultural life.

Considering the relationship between socio-economic and migration processes, it is necessary to take into account the theory of factors that are the causes of "repulsion" or "attraction". The theory of factors of "attraction repulsion" was developed by E. Ravenstein [5], who formulated the "Laws of migration" on the basis of census data in England and Wales at 19th century. E. Ravenstein concluded that migration can be explained by factors of "attraction - repulsion" and unfavourable conditions in one region (strict legislation, excessive taxes, etc.), "displace" people from their residence place as well as favorable conditions created in other regions, which "attract" them.

E. Ravenstein divided all the factors of migration into internal (push factors) and external (pull factors), which can be divided into five groups, namely: economic, social, cultural, political and environmental. Among the economic factors, it is worth mentioning, first of all, the level of wages, the quality of life, the level of unemployment, the stability of economic development and the type of tax system.

The migration laws formulated by E. Ravenstein were as follows: the main reason for migration is better conditions in another locality than in the one where the person lives; the extent of migration decreases with increasing distance; migration often occurs in several stages; population migration is two-way; people's mobility is determined by their personal characteristics (gender, age, social class, etc.).

Also, the density and volume of migration flows are influenced by the structural changes that occur in social and economic systems related to the cyclicality of the economy, the technological transition and the mismatch of requests (needs) of the National Labour Market Structure for Highly Qualified Professionals [6].

Consequently, the impact of migration processes on the social and economic development of certain regions, countries and their associations is beyond doubt, and scientists and public administrators need to have tools, which would make it possible to develop effective employment policies, to identify possible losses, imbalances and profits for the State from migration flows, to form social packages of support for forced migrants, to improve migration policies etc.
In view of the above, the issues of modelling and forecasting migration flows in the face of globalization challenges are of particular relevance. Considerable attention is paid to the outlined scientific problem in the research of foreign and domestic scientists. Thus, in the work of [7] using the simulation method, namely system dynamics, a system of causal relationships has been constructed, and the main factors influencing the decision of individuals to travel abroad have been identified. In the proposed model two feedback loops are presented, one of them reinforcing (reinforcing loop) and the other - counteracting (counteracting loop). It is the counteracting loop that allows the system after numerous iterations, occurring continuously dynamically in each period, to reach a balance.

Econometric methods and models, namely regression analysis methods, are the most commonly used in studies on migration processes at the regional and national levels. This method is the basis for forecasting and for studying the impact of various objective factors on the dynamics and volumes of migration flows. In scientific researches $[8,9]$ in constructing regression models, it has been proved that the main factors influencing migration processes are the index of average wages, GDP per capita, labour demand, employment and unemployment, Provision of social benefits, employers' need for workers to replace vacant jobs.

In [10] an approach is proposed for modeling the business climate of countries using the taxonomy method. The resulting model can be used to increase the choice of influencing factors when modeling the attractiveness of countries for migrants.

The authors [11] investigate the possibilities of applying machine learning methods to modeling macroeconomic indicators which have impact on migration processes.

Also in the research [12] the authors applied the method of statistical spatial modelling, taking into account heterogeneous influences on migration flows, visualized the spatial distribution of net migration, indexes of the internal and external flows among the municipalities of the Brazilian Amazon. The authors have shown that the selected variables demonstrate spatial relationships, and spatial regression models provide more accurate estimates of the indexes by including autoregression with spatial lag.

In some researches $[13,14]$ authors use a cluster analysis to study migration flows, the results of which confirm that the development of individual regions (countries) is uneven and asymmetrical in terms of the main indicators of labour migration, as well as being the basis for the search for cluster convergence directions.

In the research [15] the author applies web-based analysis techniques to research international migration flows when the network is seen as a set of nodes (countries) and arcs with some directions. The migration process is viewed as a socio-spatial network that has a set of nodes located in a geographical space and interconnected ribs of arcs with a certain length. This method allowed the author to identify certain patterns of international migration (asymmetric and reciprocal) and migration clusters. 
Through the dynamic multi-factor model based on the assumptions of the theory of positional games, the authors of the study [16] carried out a prediction of the migration behaviour of the individual depending on the economic situation. The impact of migration on the socio-economic development of the recipient country through the CobbDouglas production function is also assessed.

Using the agent modelling methodology, the authors of other research [17] proved that it is a reliable method of modelling autonomous human behaviour in migration decisions, taking into account not only socio-economic influences but also environmental ones.

It is also suggested that agent models should be applied in situations where human behaviour needs to be investigated in conflict situations affecting migration decisions internally displaced persons, refugees, undocumented migrants [18]. This concept makes it possible to construct adequate models of the movement of forced migrants and to forecast their likely places of residence, which will enable the public authorities of the State to deal effectively and in a timely manner with the problems of housing and social guarantees, employment and so on.

Using the structural vector autoregression and the estimated model of the dynamic stochastic general equilibrium (DSGE) of a small open economy, the authors of the research [19] conclude that migration shocks have a significant impact on the volatility of GDP per capita, to replace investment income per capita as well as investment housing and housing.

In summary, contemporary globalization processes have led to the emergence of a new pattern of historical migratory movements and flows, which has led to the emergence of new mega trends. Therefore, traditional methods of analysis and modelling do not always allow for an adequate assessment and forecasting of these processes, hence the need to apply fuzzy logic methodology, that would allow ranking countries according to their migration attractiveness in an uncertain environment.

\section{Research methods}

As noted above, it is useful to use a fuzzy inference engine in the form of a fuzzy set, which corresponds to the current values of the input variables, using fuzzy knowledge base and fuzzy operations, to assess migration processes. Fuzzy sets theory is used specifically to solve problems in which the input data is unreliable and poorly formalised. Currently, fuzzy logic is used in the construction of neural networks, genetic algorithms, and the design of fuzzy systems. Fuzzy logic provides effective means of representation of uncertainty and inaccuracies of the real world, and the presence of mathematical means of representation of uncertainty of input information makes it possible to construct models corresponding to realities [20].

The foundations of the fuzzy sets theory of and fuzzy logic were laid in the 1960 s by Lutfi A. Zadeh [21]. Thanks to this research a new scientific branch has appeared, which received the name "fuzzy logic". His work laid the foundations for the approximate human reasoning modeling and gave impetus to the development of a new mathematical theory. L. Zadeh introduced the term "fuzzy set", suggesting that the ownership function can accept any value within $[0 ; 1]$ not just the values of 0 or 1. Also, a series of operations on fuzzy sets has been defined and a generalization of known methods of logical inference has been proposed by introducing the notion of a linguistic variable.

A fuzzy inference engine used in expert and knowledge-based management systems, established subject matter experts or learning neural networks. In turn, the training set of networks is based on experimental data as a set of fuzzy predicate rules of the form:

Rule 1: if $x \in A_{1}$, than $y \in B_{1}$,

Rule 2: if $x \in A_{2}$, than $y \in B_{2}$,

...

Rule $N$ : if $x \in A_{n}$, than $y \in B_{n}$, where $x$-input variable, $y$ - output variable, $A$ and $B-$ membership functions defined accordingly $x$ and $y$.

Expert $A \rightarrow B$ knowledge, reflecting the unclear causal relationship between input and output, is called fuzzy connections $R$ :

$$
R=A \rightarrow B,
$$

where " $\rightarrow$ " is called fuzzy implication.

The relation $R$ can be seen as a fuzzy subset of a direct product $X \times Y$ of a complete set of assumptions $X$ and inferences $Y$. Thus, the process of obtaining a fuzzy output $B^{\prime}$ with observation $A^{\prime}$ and knowledge $A B$ represented as follows:

$$
B^{\prime}=A^{\prime} \cdot R=A^{\prime} \cdot(A \rightarrow B),
$$

where "." - convolution operation [22].

Fuzzy inference algorithms differ in the type of rules, logical operations, and dephasation methods. The most common modifications to the fuzzy inference algorithm are the Mamdani and Sugeno algorithms. The main difference between the two is the way the values of the output variable in the rules are specified, and the knowledge base. In Mamdani-type systems, the values of the input variables are given by fuzzy terms, in Sugeno-type systems it is as a linear combination of the input variables. For tasks where identification is more important, it is useful to use Sugeno algorithm, and for tasks where explanation and justification are more important, Mamdani algorithm will have the advantage.

Mamdani algorithm was one of the first to be used in fuzzy output systems [23]. Formally, Mamdani algorithm can be defined as follows.

Let the knowledge base contain only two fuzzy rules of the kind:

Rule 1: if $x \in A_{1}$ and $y \in B_{1}$, than $z \in C_{1}$,

Rule 2: if $x \in A_{2}$ and $y \in B_{2}$, than $z \in C_{2}$,

where $x, y$-names of the input variables, $z$ - name of the output variable, $A_{1}, A_{2}, B_{1}, B_{2}, C_{1}, C_{2}$ - some fuzzy sets, assigned by membership functions $\mu_{A_{1}}(x), \mu_{A_{2}}(x), \mu_{B_{1}}(y)$, $\mu_{B_{2}}(y), \mu_{C_{1}}(z), \mu_{C_{2}}(z)$, the precise value of $z_{0}$ should be determined on the basis of the information given and the clear values $x_{0}, y_{0}$. 
The operation of implication of fuzzy sets consists of the following four steps:

1. Fuzziness: The degrees $\mu_{A_{1}}\left(x_{0}\right), \mu_{A_{2}}\left(x_{0}\right), \mu_{B_{1}}\left(y_{0}\right)$, $\mu_{B_{2}}\left(y_{0}\right)$ of each premise of each rule. The ownership functions defined on the input variables apply to their actual values to determine the degree of truth of each premise of each rule.

2. Fuzzy inference: there are "cut" level for the assumptions of each of the rules (using min operation). The calculated meaning of truth for the assumptions of each rule applies to the conclusions of each rule. This results force one fuzzy subset that will be assigned to each output variable for each rule.

$$
\alpha_{1}=\mu_{A_{1}}\left(x_{0}\right) \cap \mu_{B_{1}}\left(y_{0}\right), \alpha_{2}=\mu_{A_{2}}\left(x_{0}\right) \cap \mu_{B_{2}}\left(y_{0}\right),
$$

where " $\cap$ " is the operation of the logical minimum ( $\min )$.

Then there are "cut" membership functions:

$$
\mu_{C_{1}}^{\prime}(z)=\left(\alpha_{1} \cap \mu_{C_{1}}(z)\right), \mu_{C_{2}}^{\prime}(z)=\left(\alpha_{2} \cap \mu_{C_{2}}(z)\right) .
$$

3. Composition: using the maximum transaction ( $\max$, designated as " $U$ ") to find the found cut functions. Result is the resulting fuzzy subset for the output variable with the membership function:

$$
\mu_{\epsilon}(x)=\mu_{C}(z)=\mu_{C_{1}}^{\prime}(z) \cup \mu_{C_{2}}^{\prime}(z)
$$

4. Clarity (to find $z_{0}$ ) by centroid method:

$$
y=z_{0}=\frac{\alpha_{1} z_{1}^{*}+\alpha_{2} z_{2}^{*}}{\alpha_{1}+\alpha_{2}}
$$

where “ $\omega "$ - function domain of $\mu_{\Sigma}(x)$ [22].

\section{Results and discussions}

The United Nations estimates the number of international migrants in 2019. It has reached 272 million people. Consider the structure and trends of global labour migration processes from 1990 to 2019 (table 1), using the geographical topic [24]. In 2019, more than half of all international migrants lived in North America (82.3 million people) and Europe (59 million people). North Africa and West Asia ranks third with the largest number of international migrants (49 million people), Sub-Saharan Africa (24 million people), Central and South Asia (20 million people), and East and South-East Asia (18 million people). Latin America and the Caribbean (12 million people) and Oceania (9 million people) recorded low numbers of international migrants. Through the indexes of the average absolute increase we generated the forecast for 2025 and 2030 (table 1).

There is an upward trend in international labour migration in North America, Europe, Latin America, Oceania, Central and South Asia and South and North Africa, and a downward trend only in East and South-East Asia.
The 10 largest regional migration corridors in 2019. Presented in table 2, five of which represent nearly half of the world's migration flows (124 million people).

The "Europe to Europe" direction, which has 4.19 million people international migrants, is the largest regional migration corridor in the world. A large proportion of these migrants have moved between European Union countries. In 2010-2019, it increased by more than 5 million people international migrants, compared to 2000 2010 , with an average annual increase of more than 0.5 million people.

The direction "Latin America and the Caribbean to North America" is the second largest regional migration corridor in 2019 (26.6 million people people). During the period 1990-2000, in this direction the number of migrants increased by 0.9 million people per year, but the growth slowed between 2000-2010 and 2010-2019 (0.5 and 0.3 million people per year, respectively).

The next three largest regional migration directions were almost the same in 2019 (18-19 million people international migrants). The number of international migrants inside the corridor "North Africa and West Asia" increased by 7.3 million people in 2010-2019, while the corridor "Central and South Asia to North Africa and West Asia" increased by 5.4 million people.

While international migration is a global phenomenon, only 20 countries received two thirds of all international migrants in 2019. Almost half of all international migrants live in 10 countries only. The largest number of migrants is in the United States of America, with 51 million people migrants, or about $19 \%$ of the world's total number of migrants admitted in 2019. The most attractive countries for migration in 2019 were Germany (13.1 million people) and Saudi Arabia (13.1 million people), the Russian Federation (12 million people) and the United Kingdom (10 million people). Of the 20 most attractive countries for migration, seven are in Europe, four - in North Africa and Western Asia, three - in Central and South Asia, two - in East and South-East Asia and North America, and one each in Oceania and Sub-Saharan Africa.

Between 1990 and 2019, the United States recorded the largest absolute increase in international migrants (27.4 million people). The countries with the largest increases were Saudi Arabia (8.1 million people per year), the United Arab Emirates (7.3 million people per year), Germany (7.2 million people per year) and the United Kingdom (5.9 million people per year).

In 2019 one third of all international migrants come from only 10 countries. In 2019 India has become the leading country of the international migrants origin (17.5 million people). The second largest migrants contributor was Mexico (11.8 million people), followed by China (10.7 million people), the Russian Federation (10.5 million people) and the Syrian Arab Republic (8.2 million people).

Thus, based on data on the volume and intensity of migration processes, it can be concluded that different regions and countries have different attractions for migrants.

The level of the migration attractiveness of countries was determined through the Mamdani fuzzy inference. 
Table 1. Labour migration by geography, 1990-2019, mil. people and forecast for 2025, 2030 [24]

\begin{tabular}{lcllccccc}
\hline Years & \multicolumn{9}{c}{ Countries } \\
\cline { 2 - 8 } & $\begin{array}{c}\text { North Africa } \\
\text { and } \\
\text { West Asia }\end{array}$ & South Africa & $\begin{array}{c}\text { Central and } \\
\text { South Asia }\end{array}$ & $\begin{array}{c}\text { East and } \\
\text { Southeast } \\
\text { Asia }\end{array}$ & Oceania & $\begin{array}{c}\text { Latin America } \\
\text { and } \\
\text { the Caribbean }\end{array}$ & Europe & $\begin{array}{c}\text { North } \\
\text { America }\end{array}$ \\
\hline 1990 & 4.73 & 7.16 & 6.84 & 26.17 & 13.29 & 17.61 & 27.61 & 49.61 \\
1995 & 5.02 & 6.69 & 8.34 & 21.25 & 14.28 & 18.91 & 33.34 & 53.49 \\
2000 & 5.36 & 6.57 & 10.51 & 20.47 & 13.15 & 20.32 & 40.35 & 56.86 \\
2005 & 6.02 & 7.22 & 12.95 & 18.96 & 14.22 & 23.28 & 45.36 & 63.59 \\
2010 & 7.13 & 8.26 & 15.75 & 19.58 & 15.86 & 32.56 & 50.97 & 70.68 \\
2015 & 8.07 & 9.44 & 17.87 & 19.44 & 21.34 & 42.05 & 55.63 & 75.01 \\
2020 & 8.93 & 11.67 & 18.30 & 19.63 & 23.57 & 48.59 & 58.65 & 82.30 \\
2025 (Forecast) & 9.63 & 12.42 & 20.21 & 18.54 & 25.28 & 53.75 & 63.82 & 87.75 \\
2030 (Forecast) & 10.33 & 13.17 & 22.12 & 17.45 & 26.99 & 58.91 & 68.99 & 93.20 \\
\hline
\end{tabular}

Table 2. Largest regional labour migration corridors in the world in 2019, mil. people [24]

\begin{tabular}{llll}
\hline oo & Contributing countries groups & Recipient countries groups & Number of migrants \\
\hline 1 & Europe & Europe & 41.86 \\
2 & Latin America and the Caribbean & South America & 26.58 \\
3 & North Africa and West Asia & North Africa and West Asia & 18.93 \\
4 & Central and South Asia & North Africa and West Asia & 18.52 \\
5 & South Africa & South Africa & 18.31 \\
6 & East and Southeast Asia & East and Southeast Asia & 14.32 \\
7 & North Africa and West Asia & Europe & 13.05 \\
8 & Central and South Asia & Europe & 11.20 \\
9 & East and Southeast Asia & North America & 10.24 \\
10 & Latin America and the Caribbean & Latin America and the Caribbean & 8.24 \\
\hline
\end{tabular}

The fuzzy inference simulation process was conducted in the Matlab environment using the Fuzzy Logic Toolbox. To construct the Mamdani fuzzy inference system, four input and one output (linguistic) variables in the fuzzy inference system were specified: GDP (gross domestic product per capita), IR (inflation rate), UR (unemployment rate), PIT (personal income tax) and EMA (Evaluation of migration attractiveness) (figure 1). These variables were selected from correlation and regression analysis as relevant to the migration attractiveness of countries.

The phasing of the introduced linguistic variables and the definition of their terms have been carried out. The parameters of the membership functions for these term sets are shown in table 3 and the structure of the functions are shown in figure 2.

Based on the rules, a decision-making mechanism is created, predicts the value of the performance variable. The peculiarity of this model is its flexibility, it can be filled with other rules, its content and quantity adjusted.

On the basis of the input variables statistics an evaluating of migration attractiveness was calculated. Figure 3 illustrates Mamdani fuzzy inference with the example of France. The results of the evaluation of migration attractiveness of selected countries are presented in table4.

The analysis of the recipient countries rating allows to draw conclusions that none of the studied countries has received the score «ultrahigh». Italy, France and the United Arab Emirates are among the top three most attractive countries with a «high» term. The middle-level attrac-

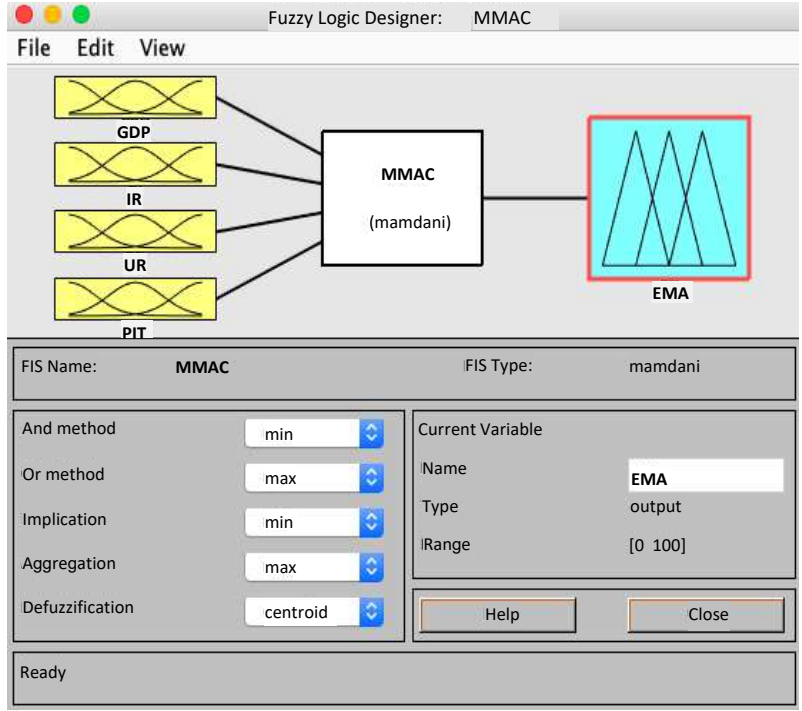

Figure 1. Structure of the model of the evaluation the labour migration attractiveness of countries in 2019 through the Fuzzy Logic Toolbox

tion cluster is Saudi Arabia, the UK, Canada, the US, and Australia. Russia has the lowest rating. The results are largely consistent with the statistical analysis, but allow for a clearer definition of a country's ranking. It should be noted that the proposed fuzzy model for the evaluating the migration attractiveness of recipient countries can be fur- 


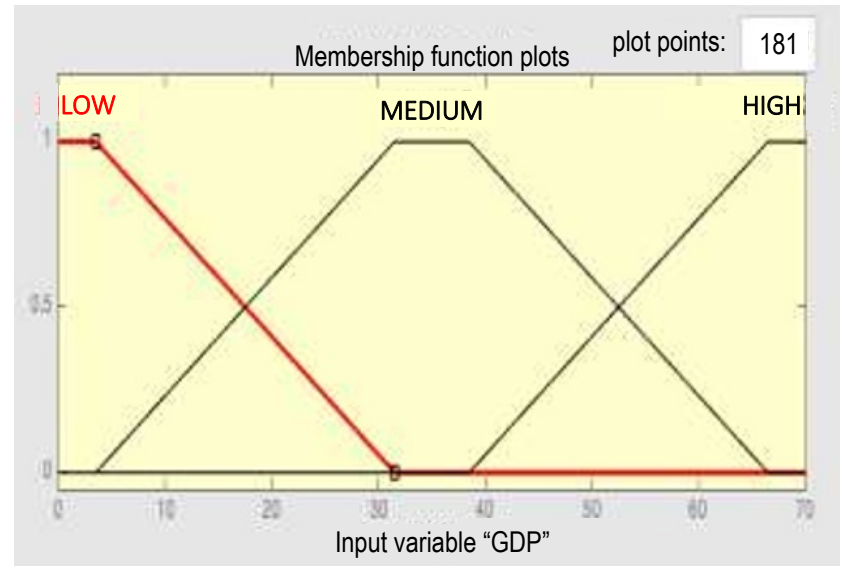

a)

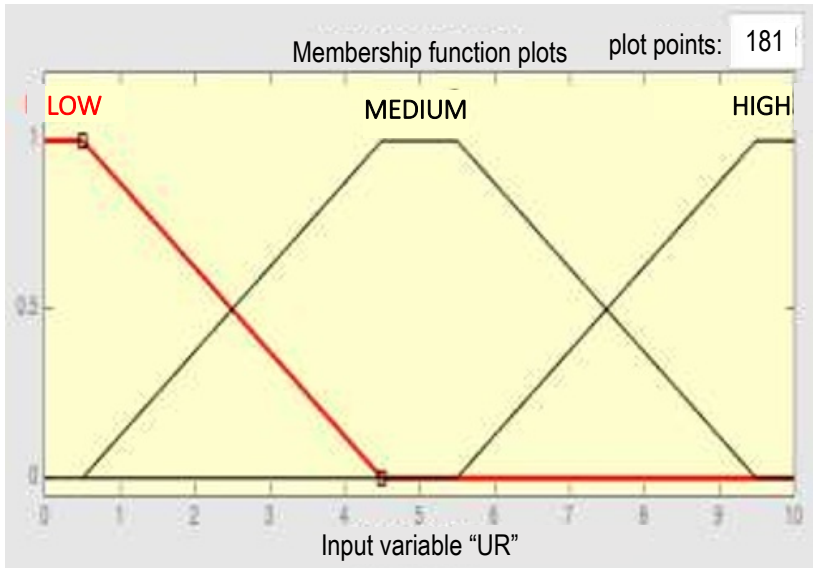

c)

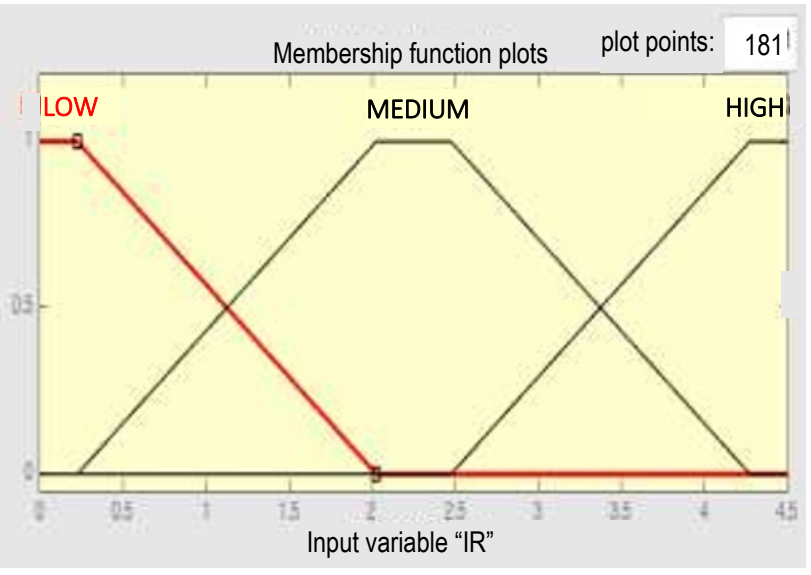

b)

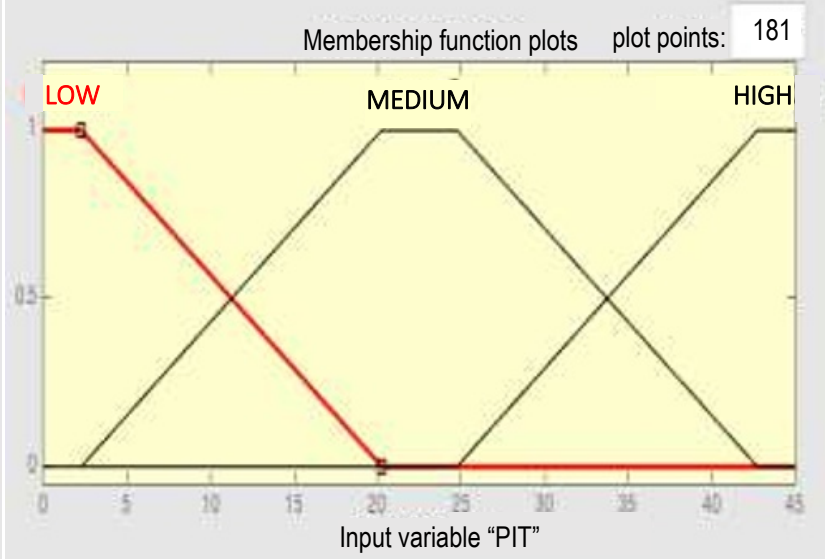

d)

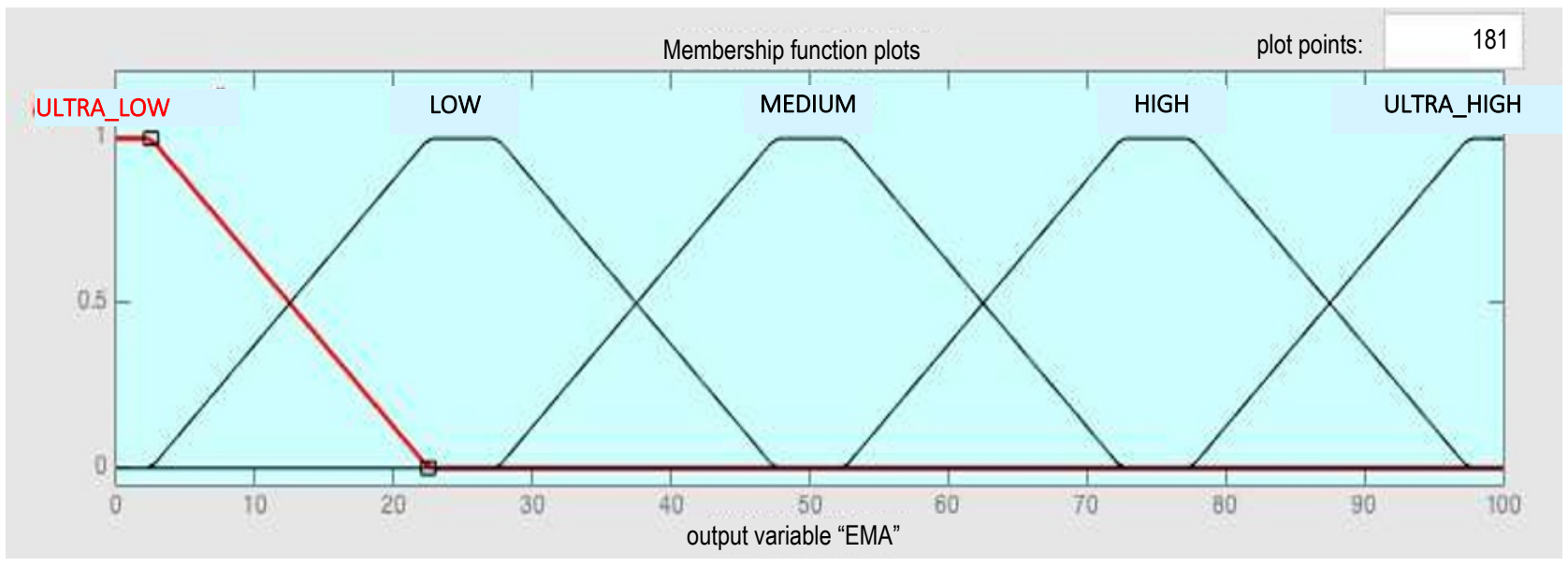

e)

Figure 2. Membership function graphs for input (a, b, c, d) and output (e) linguistic variables

ther developed and refined by introducing additional input variables.

\section{Conclusion}

Thus, using the Mamdani fuzzy inference method, a system has been developed that allows to make a decision on 
Table 3. Attributes of the attribution model of the evaluation the labour migration attractiveness of countries in 2019

\begin{tabular}{llll}
\hline $\begin{array}{l}\text { Linguistic } \\
\text { variable }\end{array}$ & $\begin{array}{l}\text { Evaluating } \\
\text { interval }\end{array}$ & Term & $\begin{array}{l}\text { Evaluating } \\
\text { rate }\end{array}$ \\
\hline \multirow{2}{*}{ GDP (thousand \$) } & {$[0 ; 70]$} & low & $0-23.3$ \\
& & $\begin{array}{l}\text { medium } \\
\text { high }\end{array}$ & $\begin{array}{l}23.3-46.6 \\
46.6-70\end{array}$ \\
& & low & $0-1.5$ \\
IR (\%) & {$[0 ; 4.5]$} & medium & $1.5-3$ \\
& & high & $4-4.5$ \\
& & low & $0-3.3$ \\
UR (\%) & {$[0 ; 10]$} & medium & $3.3-6.6$ \\
& & high & $6.6-10$ \\
PIT $(\%)$ & {$[0 ; 45]$} & low & $0-15$ \\
& & medium & $15-30$ \\
& & high & $30-45$ \\
& & ultralow & $0-20$ \\
EMA & low & $20-40$ \\
& & medium & $40-60$ \\
& & high & $60-80$ \\
& & ultrahigh & $80-100$ \\
\hline
\end{tabular}

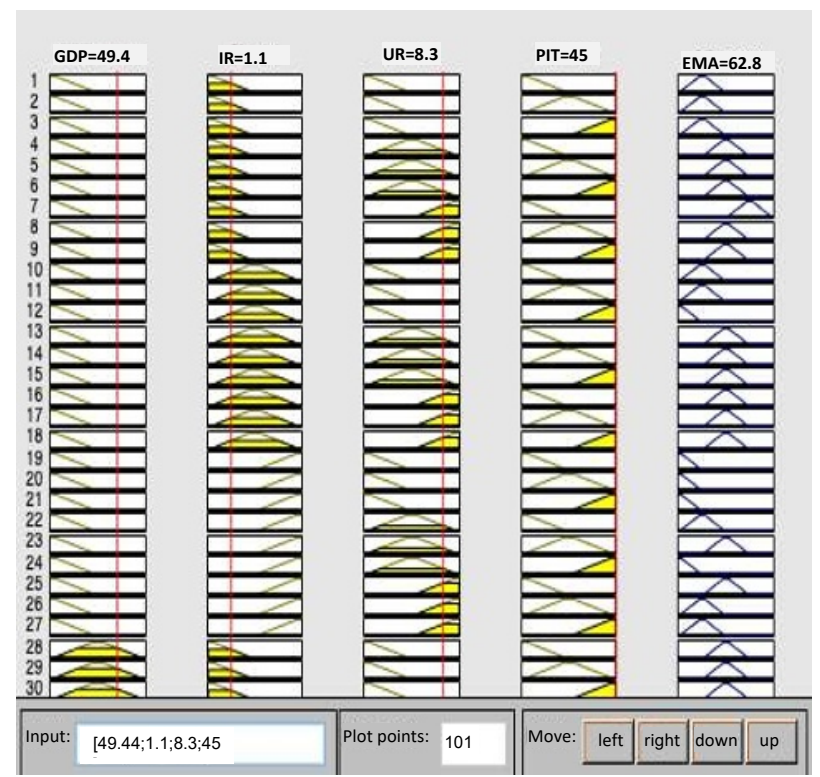

Figure 3. Implementation of Mamdani fuzzy inference using Fuzzy Logic Toolbox of Matlab package

the selection of the optimal country for labour migration based on the analysis of the most popular recipient countries in 2019. The parameters of the Mamdani model are interpreted quite easily, and the use of fuzzy logic makes it possible to model economic problems effectively in order to analyse the economic indicators of the migration attractiveness of countries. As a result of the implementation of this model, recipient countries are ranked as being the most attractive for migrant employees. Such countries as Italy, France and the United Arab Emirates, which have medium and high levels of per capita GDP, low inflation, and a "loyal" level of tax, were in the first three positions.
Table 4. Rating of recipient countries' attractiveness to international labour migration, 2019 [24-28]

\begin{tabular}{lllllll}
\hline & \multicolumn{3}{c}{ Input variables } & \multicolumn{3}{c}{$\begin{array}{l}\text { Output } \\
\text { vari- } \\
\text { able }\end{array}$} \\
\cline { 2 - 6 } Country & $\begin{array}{l}\text { GDP, } \\
\text { thou- } \\
\text { sand }\end{array}$ & $\begin{array}{l}\text { IR, } \\
\text { \% }\end{array}$ & $\begin{array}{l}\text { UR, } \\
\%\end{array}$ & $\begin{array}{l}\text { PIT, } \\
\%\end{array}$ & EMA & Rank \\
& $\$$ & & & & & \\
& 44.20 & 0.6 & 9.8 & 43 & 68.9 & 1 \\
Italy & 49.44 & 1.1 & 8.3 & 45 & 62.8 & 2 \\
France & 69.90 & 1.9 & 2.4 & 0 & 60.3 & 3 \\
United Arab & & & & & & \\
Emirates & 48.91 & 2.1 & 5.9 & 0 & 58.3 & 4 \\
Saudi Arabia & 48.71 & 1.7 & 4.1 & 45 & 56.3 & 5 \\
Great Britain & 51.34 & 1.9 & 5.4 & 33 & 52.9 & 6 \\
Canada & 65.12 & 1.8 & 3.9 & 37 & 52.5 & 7 \\
USA & 56.05 & 1.4 & 3 & 45 & 51.1 & 8 \\
Germany & 53.32 & 1.6 & 5.3 & 45 & 50 & 9 \\
Australia & 29.18 & 4.5 & 4.4 & 13 & 46.6 & 10 \\
Russia & & & & & & \\
\hline
\end{tabular}

The model could be improved to reflect global trends in 2020 and the impact of the pandemic on global migration flows.

\section{References}

[1] D.S. Massey, Patterns and processes of international migration in the 21st century, in Conference on African Migration in Comparative Perspective, Johannesburg, South Africa, 4-7 June, 2003 (2003), http://citeseerx.ist.psu.edu/viewdoc/ download?doi=10.1.1.473.925\&rep=rep1\& type $=p d f$

[2] E. Scherbakova, Demoskop Weekly (2006)

[3] M.J. Miller, S. Castles, The age of migration: International population movements in the modern world (Palgrave Macmillan Basingstoke, Hampshire, 2009)

[4] T.J. Hatton, J.G. Williamson, NBER Working Paper (2002)

[5] E.G. Ravenstein, Journal of the Royal Statistical Society 52, 241 (1889)

[6] L. Serhieieva, O. Kovtun, A. Opalenko, O. Ivanylova, International Journal of Industrial Engineering \& Production Research 31, 625 (2020)

[7] A. Novik, Ekonomika ta derzhava 4, 119 (2019)

[8] M. Averkyna, A.Kudrei, Pryazovskyi ekonomichnyi visnyk 1 (2020)

[9] O. Ovchinnikova, Intelekt XXI 4, 27 (2017)

[10] D. Ocheretin, V. Los, H. Kucherova, O. Bilska, E3S Web of Conferences 166, 13024 (2020)

[11] V. Babenko, A. Panchyshyn, L. Zomchak, M. Nehrey, Z. Artym-Drohomyretska, T. Lahotskyi, WSEAS Transactions on Business and Economics 18, 209 (2021) 
[12] D. Sathler, S. Adamo, E.E. Lima, D. Macedo, A. de Sherbinin, P. Kim-Blanco, Applied Geography 109 (2019)

[13] I. Aksonova, V. Derykhovska, in State management and administration, service sector, economy and international relations as the driving force of economic growth states of the XXI century, edited by M. Goldenblatt (European science platform, Vinnytsia, 2020), 1st edn.

[14] I. Porat, L. Benguigui, Physica A: Statistical Mechanics and its Applications 561, 125210 (2021)

[15] H. Akbari, Social Networks 64, 181 (2021)

[16] A.A. Tarasyev, J.B. Jabbar, IFAC-PapersOnLine 51, 407 (2018)

[17] D. Kniveton, C. Smith, S. Wood, Global Environmental Change 21, 534 (2011)

[18] C. Searle, J. van Vuuren, Computers, Environment and Urban Systems 85, 101568 (2021)

[19] C. Smith, C. Thoenissen, Journal of Economic Dynamics and Control 109, 103781 (2019)

[20] A.G. Korchenko, Building information security systems on fuzzy sets. Theory and practice (EMK-Pres, 2006)
[21] L.A. Zadeh, Information and Control 8, 338 (1965)

[22] A.V. Leonenkov, Fuzzy modeling in MATLAB and FUZZY TECH, 736 (BHV Peterburg, SPb, 2005)

[23] E.H. Mamdani, Proc. IEEE 121, 185 (1974)

[24] United Nations, International migrant stock: the 2019 revision (2020), https://www.un.org/en/ development/desa/population/migration/ data/estimates2/estimates19.asp

[25] World Bank, GDP per capita from world development indicators database (2020), https://data. worldbank. org/indicator/ NY . GDP . PCAP . PP . CD? end $=2019 \&$ start $=2019$

[26] World Bank, Inflation of consumer prices from International Monetary Fund (2020), https://data. worldbank.org/indicator/FP.CPI. TOTL. ZG

[27] World Bank, Unemployment rate from International Labour Organization, ILOSTAT database (2020), https://data. worldbank .org/indicator/SL. UEM. TOTL . ZS

[28] TRADING ECONOMICS, List of countries by personal income tax rate (2020), https: //tradingeconomics.com/country-list/ personal-income-tax-rate 